\title{
Graph Theoretical Analysis, Insilico Modeling and Formulation of Pyrimidine Nanoparticles as p38 $\alpha$ MAP Kinases inhibitors: A Quantitative Proteomics Approach
}

Authors

Panneerselvam Theivendren ${ }^{1}$, Selvaraj Kunjiappan², Saravanan Govindraj ${ }^{3}$, Jaikanth Chandrasekarn ${ }^{4}$, Parasuraman Pavadai ${ }^{5}$, Ganesan Rajalekshmi Saraswathy ${ }^{6}$, Indhumathy Murugan ${ }^{7}$

\section{Affiliations}

1 Department of Pharmaceutical Chemistry, Karavali College of Pharmacy, Vamanjoor, Mangalore, Karnataka, India

2 Sir C.V. Raman Krishnan International Research Centre, Kalasalingam University, Krishnankoil, Tamilnadu, India

3 Department of Pharmaceutical Chemistry, MNR College of Pharmacy, Fasalwadi, Sangareddy, Telangana, India

4 Department of Pharmacology, Karavali College of Pharmacy, Vamanjoor, Mangalore, Karnataka, India

5 Department of Pharmaceutical Chemistry, Faculty of Pharmacy, M S Ramaiah University of Applied Sciences, M S R Nagar, Bengaluru, Karnataka, India

6 Pharmacological Modelling and Simulation Centre, Faculty of Pharmacy, M S Ramaiah University of Applied Sciences, M S R Nagar, Bengaluru, Karnataka, India

7 Department of Biotechnology, P.S.R Engineering College, Sevalpatti, Sivakasi, Tamilnadu, India

Key words

Graph Theoretical Analysis, Insilico Modeling,

Response Surface Methodology, Pyrimidine Nanoparticles, Anticancer activity, Quantitative Proteomics

received 06.04.2018

accepted 25.06.2018

\section{Bibliography}

DOI https://doi.org/10.1055/a-0650-3979

Published online: 24.7.2018

Drug Res 2019; 69: 100-110

(c) Georg Thieme Verlag KG Stuttgart · New York

ISSN 2194-9379

\section{Correspondence}

Dr. T. Panneerselvam

Professor, Department of Pharmaceutical Chemistry

Karavali College of Pharmacy

Vamanjoor, Mangalore- 575028

Karnataka

India

Tel.: + 91/759/8224818

tpsphc@gmail.com 丹upporting Information for this article is available online at http://www.thieme-connect.de/products

\begin{abstract}
In this study, the optimized 4-(4-hydroxybenzyl)-2-amino6-hydroxypyrimidine-5-carboxamide derivative was formulated as nanoparticles to evaluate for their anticancer activity. The response surface methodology (RSM) was performed with utilization of Box-Behnken statistical design (BBSD) to optimize the experimental conditions for identification of significant synthetic methodology. To explore the stability of the derivative was done by density functional theory (DFT). Graph theoretical analysis was introduced to identify the drug target p38 $\alpha$ MAP Kinases and then insilico modeling was performed to provide straightforward information for further structural optimization. The experimental results under optimal experimental conditions obtained $74.55-76 \%$ yield of 4-(4-hydroxybenzyl)-2-amino6-hydroxypyrimidine-5-carboxamide, $127 \mathrm{oC}$ melting point and Rf value 0.59 were well matched with the predicted results and this was gaining $95 \%$ of confidence level and suitability of RSM. The spectral data were reliable with the assigned structures of synthetic yields. The formulated nanoparticles were exhibited a good anticancer activity against used cancer cell line MCF7. Amusingly the observed docking scores and in-vitro anticancer activity was proving the compound significance and potential as a potent $p 38 \alpha$ inhibitor. Further, we have elucidated the mechanism of action at its functional level using label-free quantitative proteomics. Interestingly the observed results were indicating that the derived proteomics data involving in the alteration process in cancer-related regulatory pathways.
\end{abstract}




\section{Introduction}

Despite the fact that, the choice of easily reached and pharmacophoric heterocycles is fairly limited, the development of novel, fast, and healthy routes toward paying attention of synthesis of heterocycles are great significance. In this connection the literature review revels that, the pyrimidines and fused pyrimidines are important classes of heterocyclic compounds. They are widely used as key input to the structure construction for pharmaceutical agents and it's known to exhibit pharmacological activities like analgesic, anti-inflammatory [1, 2], anticancer [3-6], antifolates [7], antihistaminic [8], antibacterial [9], antiviral [10], hypoglycaemic [11], anticonvulsive [12], PDE4 inhibitor [13]. In addition the heterocyclic pyrimidine ring system is an extensively spread in various structural scaffolds that are present in a number of pharmaceuticals as well natural products. The unique structural collection and the highly marked pharmacological activities are displayed by this class of pyrimidine compounds have made them eye-catching synthetic targets. Led by above facts on pyrimidine chemistry, the compound 4-(4-hydroxy benzyl)-2-amino-6-hydroxypyrimidine-5-carboxamide was chosen to optimization to get significant synthetic route. The combinatorial chemistry is regularly applied into find new biologically active scaffold. In this point of view, multicomponent reactions (MCRs) are very attractive and commanding tool in the current drug discovery course that to lead findings and lead optimization [14-17]. The present study was aiming that to developing and validating 4-synthesis of (4-hydroxy benzyl)-2-amino-6-hydroxypyrimidine-5-carboxamide using response surface methodology because no work has been done so far in this particular area. The RSM is a statistical tools $[18,19]$ used to analyze quantitative data through simultaneously solve multivarient equations [20]. In this connection to perform this, there are five different parameters such as 4-hydroxy benzaldehyde $\left(\mathbf{X}_{\mathbf{1}}\right)$, ethyl cyanoacetate $\left(\mathbf{X}_{\mathbf{2}}\right)$, guanidine hydrochloride $\left(\mathbf{X}_{\mathbf{3}}\right)$, temperature $\left(\mathbf{X}_{\mathbf{4}}\right)$ and rotation per minute $\left(\mathbf{X}_{\mathbf{5}}\right)$ were chosen for investigation. The study of optimization with different independent and dependent levels was employed to look at the optimum conditions with high opinion to synthetic yields of (4-hydroxy benzyl)-2-amino-6-hydroxypyrimidine-5-carboxamide. The synthesized pyrimidine derivative was formulated as nanoparticles to enhance its therapeutic action. Mitogen Activated Protein Kinases (MAP Kinases) are very important signalling path and it involves in cell proliferation and cell death and typically it was linked with cancer cells particularly breast cancer [21-23]. The introduced graph theoretical analysis was producing information that the importance MAP Kinases and its interaction that to improve insilico modeling for identification of target especially in breast cancer agents. The optimization of pyrimidine derivatives and their structures has available in commercial market, like Uramustine, Tegafur, Floxuridine, Fluorouracil, Cytarabine, Methotrexate etc., Herein, we report the stability of designed structure 4-(4-hydroxybenzyl)-2-amino-6-hydroxypyrimidine-5-carboxamide by using DFT and its insilico screening was performed based on the results obtained from graph theoretical analysis, the identified active sites of available crystal structure of MAP Kinases (2FST) was used for docking studies. In addition to increasing our awareness of the significance of active molecule identification, the introduced graph theoretical analysis, DFT label free quantitative proteomics and approach is attractive and it is meaningful to formulate pyrimidine nanoparticles and screen them for their anticancer activity.

\section{Materials and Methods}

\section{Materials}

The graph theoretical analysis was performed by KEGG database and Cytoscape software 3.3.0. The docking study was performed by Sybyl-x version 2.0, Tripos International, St. Louis, MO, USA, 2012." The density functional theory was performed by Becke's 3-parameter exchange functional combined with Lee-Yang-Parr correlation potential (B3LYP). The molecular docking was performed with Surflex-Dock program that is interfaced with Sybyl-X 2.0. Label free quantitative proteomics was performed as described in our early publications. Briefly, agilent 1260 infinity HPLC-Chip/ MS system was used. The chemicals used for synthesis were purchased as analytical grade procured from Biotium, Inc, Aldrich Chemical Co. and Merck Chemical Co. The melting points were determined in open capillary tubes and are uncorrected. IR spectra were recorded with $\mathrm{KBr}$ pellets (FT-IR spectrometer MB $104 \mathrm{ABB}$ Limited, Kalasalingam University, Krishnankoil, Tamilnadu). ${ }^{1} \mathrm{H}$ NMR spectra (Bruker 300 NMR spectrometer, Punjab University, Chandigrah) were recorded with TMS as internal reference. Mass spectral data were recorded with a quadrupol mass spectrometer (Shimadzu GC MS QP 5000, Punjab University, Chandigrah), and microanalyses were performed using a vario EL V300 elemental analyzer (Analysensysteme $\mathrm{GmbH}$, Kalasalingam University, India). The purity of the compounds was checked by TLC on pre-coated $\mathrm{SiO}_{2}$ gel $\left(\mathrm{HF}_{254}, 200\right.$ mesh) aluminum plates (E. Merck). Evidence of structure was achieved by IR, ${ }^{1} \mathrm{H}-\mathrm{NMR}$, mass spectral data, and elemental analyses.

\section{Methods}

\section{Graph theoretical analysis}

The graph theoretical analysis was performed by using KEGG database and Cytoscape software [24]. In this study, the preparation and processing of KEGG pathway data (hsa 04010) used with different centrality measures to identify key central node of network. The overview of MAP Kinases signalling pathway from KEGG database is shown in - Fig. 1. Network components were visualized and analyzed using Cytoscape 3.3.0. Nodes are genes, compounds and edges are interaction between the nodes. The network contains 129 nodes with 177 edges.

\section{Insilico modeling}

Molecular docking was used to elucidate the binding mode of the compounds to provide straight forward information for further structural optimization. The crystal structure of mitogen activated protein kinase p38alpha (D176A + F327L) activating mutant (PDB ID: 2FST) was extracted from the Brookhaven Protein Database (PDB http://www.rcsb.org/pdb). The proteins were prepared for docking by adding polar hydrogen atom with Gasteiger-Huckel charges and water molecules were removed. The 3D sketch up of the structure was implemented by SYBYL program (Tripos Inc., St. Louis, USA) and its energy-minimized conformation was obtained with the help of the Tripos force field using Gasteiger-Huckel charges and molecular docking was performed with Surflex-Dock [25] program that is interfaced with Sybyl-X 2.0 and other miscellaneous parameters were assigned with the default values given by the software. 


\section{DFT}

The synthesized compound was studied for their stability by DFT with standard drug Uramustine. The DFT was performed through B3LYP [26] and basis set of 6-311 ++G (d,p). The above parameters have been used in the purpose of optimization and stability studies of compound and Uramustine. The optimized structures of selected compound and Uramustine were shown in > Fig. 2. In this experiment to understand the stability, highest occupied molecular orbital (HOMO) and lowest unoccupied molecular orbital (LUMO) gap, DFT reactivity parameter have been calculated and further chemical hardness also been calculated using the following formula:

$\eta=\frac{(I-A)}{2}$

Where I = ionization potential, and A = electron affinity of a molecular system. Based on Koopman's theorem [27] HOMO was related to $\mathrm{I}=-\mathrm{E}_{\mathrm{HOMO}}$ and $\mathrm{LUMO}$ was related to $\mathrm{A}=-\mathrm{E}_{\mathrm{LUMO}}$. All the calculations part was performed by using NWChem 6.0 program [28].

\section{Optimization}

The most effective key parameters on 4-hydroxy benzaldehyde $\left(X_{1}=0.1-1 M\right)$, ethyl cyanoacetate $\left(X_{2}=0.1-1 M\right)$, guanidine hydrochloride $\left(X_{3}=0.1-1 \mathrm{M}\right)$ including temperature and rotation per minute were chosen for identification of significant synthetic methodology of 4-(4-hydroxybenzyl)-2-amino-6-hydroxypyrimidine-5-carboxamide. In order to optimize the values of these parameters and reach the best response, BBSD was applied. Three levels three factors BBSD was applied to examine the optimum combination of effective synthetic methodology. The coded and real levels of the independent variables in the Box-Behnken statistical design matrix were listed in > Table 1. A total of 46 investigational runs with eight factorial points, six axial points and six replicates of the central point's were carried out according to the BBD experimental design and low, middle, and high levels of the coded values were designated for the variables as 1,0 , and -1 , respectively.

\section{Synthetic Procedure}

The synthetic strategy to prepare the target compounds is depicted in earlier reported $>$ Fig. 3 [29]. The equimolar mixture of 4-hy-

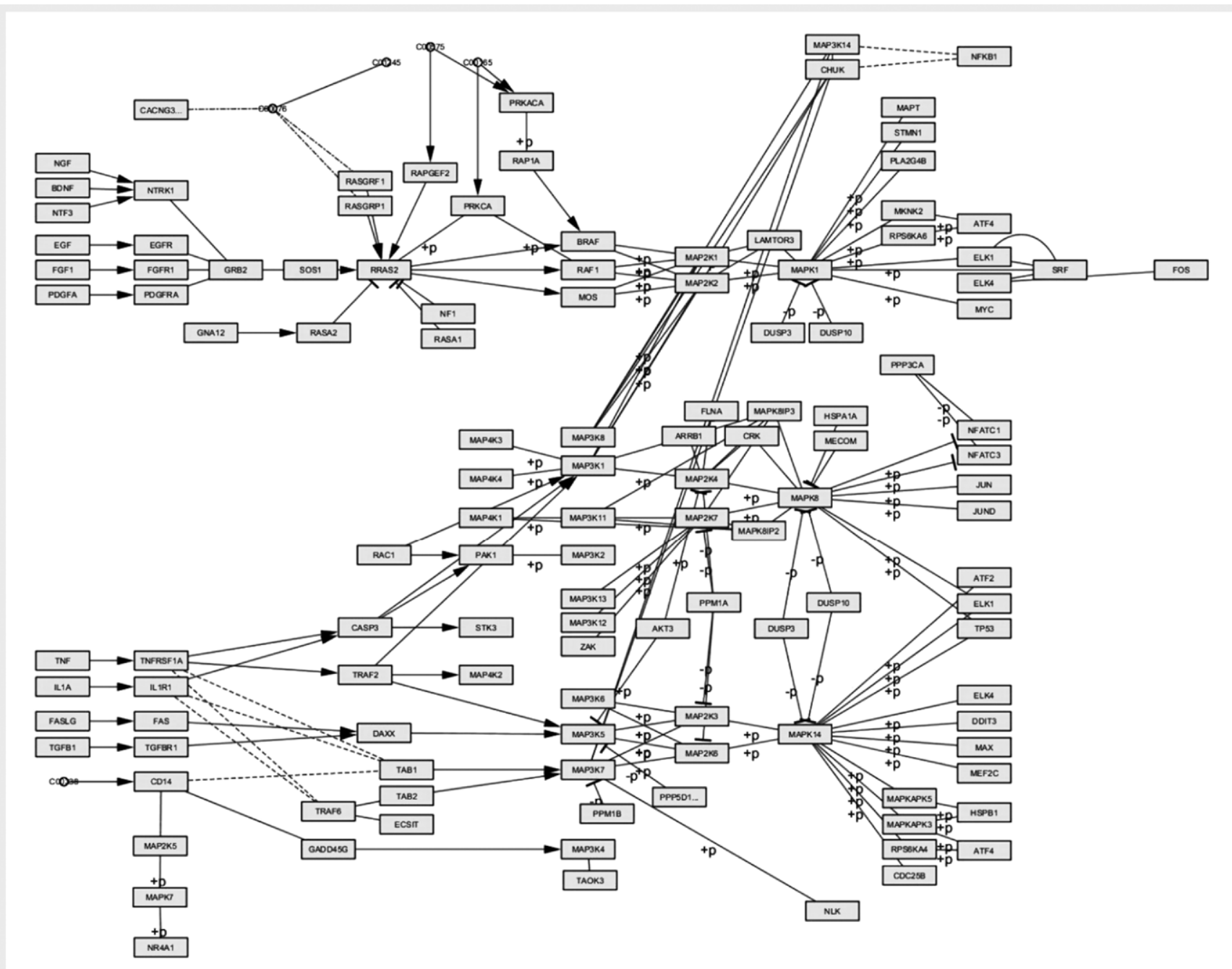

Fig. 1 The signalling pathway of MAP Kinases 
a

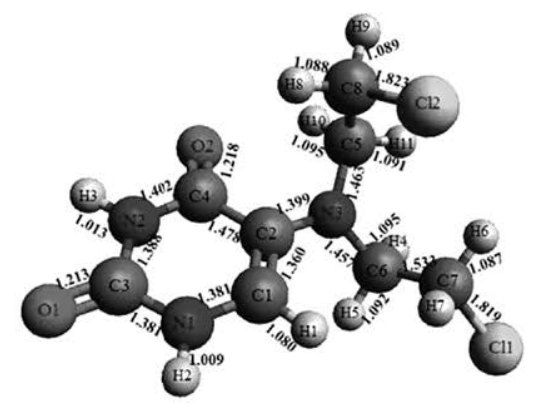

b

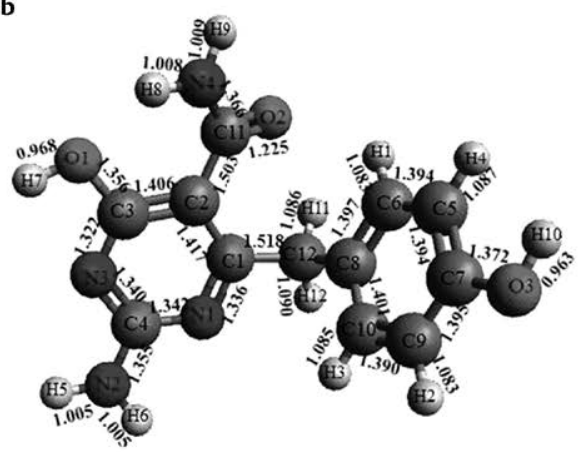

- Fig. 2 The optimized DFT structures of compound and Uramustine

- Table 1 Experimental parameters and range of coded and actual parameters of Box-Behnken statistical design (BBSD).

\begin{tabular}{|l|c|c|c|c|c|}
\hline Independent variables & Symbols $\left(x_{j}\right)$ & \multicolumn{3}{|c|}{ Factor levels } \\
\cline { 3 - 6 } & & Units & Low Actual & Medium & High Actual \\
\hline 4-hydroxy benzaldehyde & $\left(\mathrm{X}_{1}\right)$ & $\mathrm{M}$ & 0.01 & 0.055 & 0.1 \\
\hline ethyl cyanoacetate & $\left(\mathrm{X}_{2}\right)$ & $\mathrm{M}$ & 0.01 & 0.055 & 0.1 \\
\hline guanidine hydrochloride & $\left(\mathrm{X}_{3}\right)$ & $\mathrm{M}$ & 0.01 & 0.055 & 0.1 \\
\hline Temperature & $\left(\mathrm{X}_{4}\right)$ & $\mathrm{C}$ & 30 & 40 & 50 \\
\hline RPM & $\left(\mathrm{X}_{5}\right)$ & RPM & 100 & 200 & 300 \\
\hline
\end{tabular}

droxy benzaldehyde, $(0.01-1.0 \mathrm{~mol})$, ethyl cyanoacetate $(0.01-$ $1.0 \mathrm{~mol})$ and $\mathrm{NaOH}(0.4 \mathrm{~g}$ in $5 \mathrm{ml}$ water) in $25 \mathrm{ml}$ ethanol was stirred mechanically for at least $10 \mathrm{~min}$, then guanidine hydrochloride (0.01-1.0 mol) was added to the above reaction mixture and reaction mixture was stirred with 100-300 rpm using temperature 30$50^{\circ} \mathrm{C}$ till completion of reaction. Followed by the above reaction mixture was mixed with $1 \mathrm{mmol}$ of TFA in presence of $\mathrm{H}_{2} \mathrm{SO}_{4}$ in continuous stirring for $4 \mathrm{~h}$ at room temperature. After this it was poured into ice cooled water to get the desired product and to end with recrystallization using ethanol to get pure product 4-(4-hydroxy benzyl)-2-amino-6-hydroxypyrimidine-5-carboxamide.

\section{Formulation of nanoparticles}

The formulation of metal-drug nanoparticles was produced by electrolytic cathode reduction of copper and the methodology was followed by addition of $0.5 \%$ w/v of 4-(4-hydroxy benzyl)-2-amino6-hydroxypyrimidine-5-carboxamide and $5 \%$ w/v of copper sulphate penta hydrate into a $500 \mathrm{~mL}$ beaker with this $100 \mathrm{~mL}$ water was added to make a homogenous aqueous copper sulphate-drug solution. The fresh anode and cathode electrodes of copper plates were placed in this solution and 1.5 A DC a constant current was passed into this solution. At the end of the electrolyzing process a layer of copper-drug nanoparticles deposition was observed on the cathode surface. The copper-drug nanoparticles was obtained through removal of observed layer and it was washed with solution of $100 \mathrm{~mL}$ water and $60 \mathrm{~mL}$ acetone to remove residual of starting materials. The formulated nanoparticles was characterized by SEM analysis and X-ray diffraction to verify the formation of copper-drug nanoparticles.

\section{Anticancer activity}

The potential cell proliferation activity of optimally prepared 4-(4-hydroxybenzyl)-2-amino-6-hydroxypyrimidine-5-carboxamide was examined by 3-(4, 5-dimethylthiazol-2-yl)-2, 5-diphenyltetrazolium bromide (MTT) assay. Briefly, Breast cancer cell lines (MCF7 cell) were seeded in a 96 -multiwell plate $\left(1 \times 10^{5}\right.$ cells/well $)$ for $24 \mathrm{~h}$ before treatment with 4-(4-hydroxybenzyl)-2-amino-6-hydroxypyrimidine5 -carboxamide, allowing for cell add-on to the plate wall. Different concentrations of 4-(4-hydroxybenzyl)-2-amino-6-hydroxypyrimidine-5-carboxamide compound $(5-25 \mu \mathrm{g} / \mathrm{mL})$ were added to cell monolayer and the respective amount of DMSO in PBS buffer was used as control. The medium was removed after $24 \mathrm{~h}$ of treatment and cells were washed with phosphate-buffered saline (PBS, 0.01M, pH 7.4). This was followed by addition of $200 \mu \mathrm{L}(5 \mathrm{mg} / \mathrm{mL})$ of MTT prepared in serum free medium solution to each well and incubated for $4 \mathrm{~h}$ at $37^{\circ} \mathrm{C}$ in a $5 \% \mathrm{CO}_{2}$. Thus, the obtained cells were fixed, washed and stained with MTT stain. Acetic acid was used to remove excess stain while Tris EDTA buffer was used to remove any attached cells. The color intensity was measured in a microplate reader at $564 \mathrm{~nm}$. The absorption ratio of treated cells to absorption of non treated cells expressed in percentage resulted in percentage of death cells. Thus, every treatment condition was repeated in triplicate and $I C_{50}$ of 4-(4-hydroxybenzyl)-2-amino-6-hydroxypyrimidine-5-carboxamide compound obtained were used for treatment for all further studies.

\section{HPLC-Chip-MS}

The charged peptides from HPLC-Chip system were infused into mass-spectrometer for detection. The following HPLC-Chip-MS conditions were used for acquiring the MS and MS/MS spectrum of the peptides. Chip ID: G4240-62030 Chip Name: High Performance Chip, 

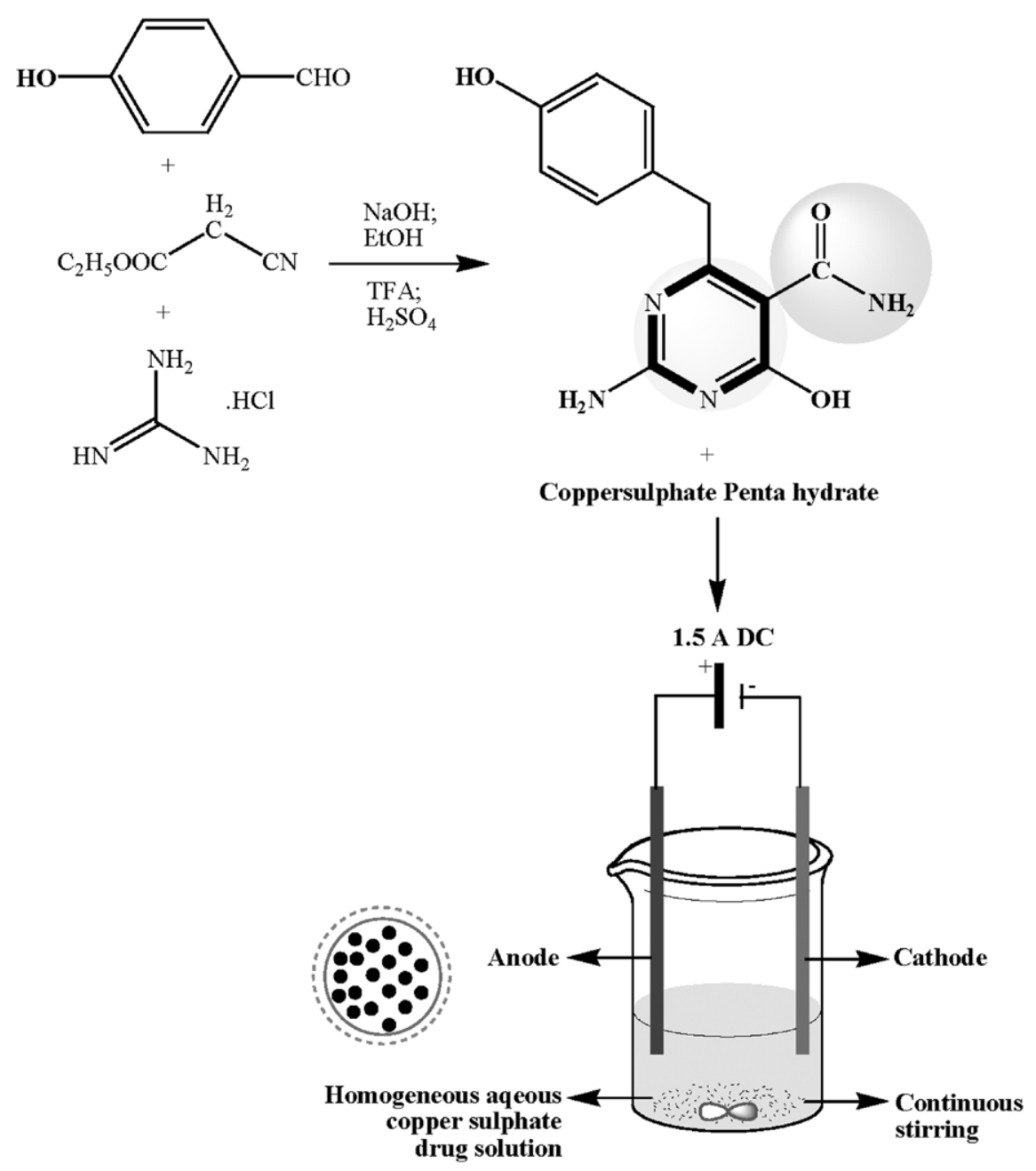

Fig. 3 Synthetic \& Formulation protocols

360 nanoliter enrichment column, $150 \mathrm{~mm} \times 75 \mu \mathrm{m}$ separation ,column Solvent A: 0.1 \% Formic Acid ,Solvent B:90\% ACN/10\% (0.1\% Formic Acid), Flow Rate: $0.3 \mu \mathrm{l} / \mathrm{min}$ Run Time: 120 minutes, Sample Volume: 5 ul ,MS Scan Range: 275 to 1700 m/z ,MS Scan Rate: 8 spectra/sec, MS/MS Scan Rate: 3 spectra/sec Ion Polarity: Positive lons Fragmentor Voltage: $170 \mathrm{~V}$, Skimmer Voltage:65 V ,Octopole RF Voltage:750V Gas ,Temperature: $250^{\circ} \mathrm{C} \&$ Drying Gas: $5 \mathrm{~L} / \mathrm{min}$.

\section{Bio-informatics analysis}

Protein identification was performed with the following criteria: (a) Trypsin digested peptides with 4 missed cleavages allowed, (b) peptide tolerance $<50 \mathrm{ppm}$, (c) $>2$ unique peptides, (d) FDR $<5 \%$. Fasta files for human proteins were downloaded from the uniprot database (Jaikanth et al., 2017). For the analysis, proteins identified in at least 2 out of 3 replicates in each group were considered. Sum of unique peptide intensity was used for semi-quantitative analysis. Ratio was calculated for proteins identified in both the treated and control groups. Ratio of $>1.5$ was considered as "up-regulated" and ratio < 0.5 was considered as down-regulated. The signaling pathway, Gene ontology and interaction network were analyzed by using open source of STRING database.

\section{Results}

\section{Graph theoretical analysis}

The network was intended to recognize key node of centrality measures like Degree, Stress, Betweenness, Radiality, Closeness, Eccentricity and Eigenvector and it was achieved by using $\mathrm{Cy}$ toscape software. The values maximum, minimum and mean were calculated for each and every protein and mean value is in use as a threshold value. In all the parameters a node of exceeds threshold values are measured as key node in network and the results were represented in > Table 2 .

\section{Insilico Modeling}

The compound and standard Uramustine were docked into the active site as shown in $>$ Fig. 4 . The predicted binding energies of the compounds are listed in $>$ Table 3 . The figure represents the interaction of Uramustine with the active site of the enzyme and observed results were showed one binding interaction at active site of the enzyme PDB ID: 2FST that is hydrogen atom of $2^{\circ}$ amine with oxygen of hydroxyl group of amino acid residue GLU71 (N-H ------ 
- Table 2 Signalling pathway of p38 $\alpha$ MAP Kinases and values of Centrality analysis.

\begin{tabular}{|c|c|c|c|c|c|c|c|}
\hline & Degree & Betweenness & Closeness & Eccentricity & EigenVector & Radiality & Stress \\
\hline Maximum value & 15 & 7868.777333 & 0.2788671 & 14 & 0.424226773 & 10.96875 & 145938 \\
\hline Mean value & 2.7 & 593.5 & 0.1801 & 10.53 & 0.0551 & 8.86 & 12789.7 \\
\hline Minimum Value & 1 & 0 & 0.11337467 & 7 & $6.38 \mathrm{E}-05$ & 5.953125 & 0 \\
\hline p38 $\alpha$ MAP Kinases & 15 & 2860.227536 & 0.19423369 & 11 & 0.234960097 & 9.5078125 & 111398 \\
\hline
\end{tabular}
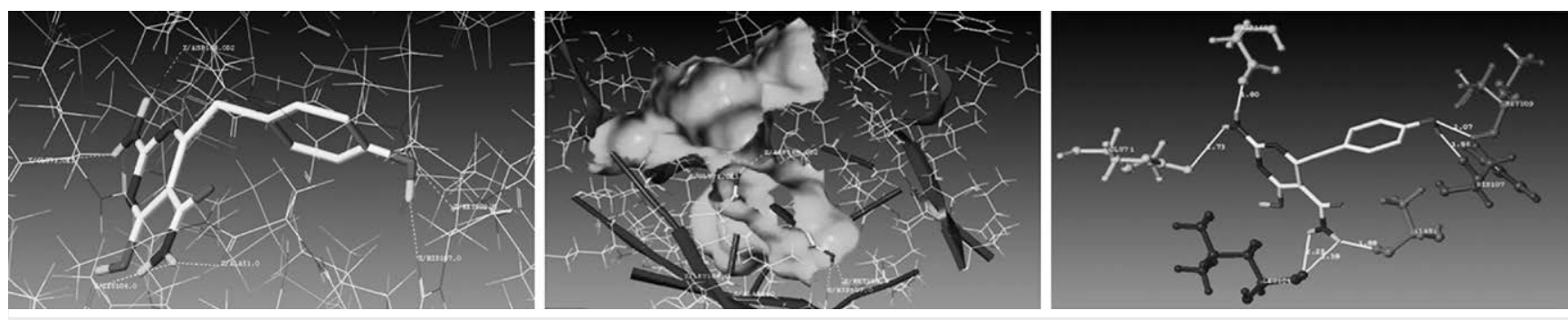

Fig. 4 The molecular interactions of compound with $\mathrm{p} 38 \alpha$ (2FST)

- Table 3 Surflex Docking score $(\mathrm{kcal} / \mathrm{mol})$ of the molecules.

\begin{tabular}{|c|c|c|c|c|c|c|c|}
\hline Compounds & C Score ${ }^{a}$ & Crash Scoreb $^{b}$ & Polar Score ${ }^{c}$ & D Scored & PMF Score ${ }^{e}$ & G Scoref & Chem Scoreg \\
\hline Uramustine & 3.38 & -0.97 & 1.28 & -81.418 & -41.487 & 25.558 & -12.468 \\
\hline Synthesized Compound & 3.35 & -2.30 & 2.44 & -109.750 & -48.087 & -206.056 & -21.777 \\
\hline \multicolumn{8}{|c|}{$\begin{array}{l}\text { aC Score (Consensus Score) integrates a number of popular scoring functions for ranking the affinity of ligands bound to the active site of a receptor } \\
\text { and reports the output of total score; ' } \text { Crash-score revealing the inappropriate penetration into the binding site. Crash scores close to } 0 \text { are favorable. } \\
\text { Negative numbers indicate penetration; 'Polar-score indicating the contribution of the polar interactions to the total score. The polar score may be } \\
\text { useful for excluding docking results that make no hydrogen bonds; d D-score for charge and van der Waals interactions between the protein and the } \\
\text { ligand; ePMF-score indicating the Helmholtz free energies of interactions for protein-ligand atom pairs (Potential of Mean Force, PMF); fG-score } \\
\text { showing hydrogen bonding, complex (ligand-protein), and internal (ligand-ligand) energies; 9Chem-score points for H-bonding, lipophilic contact, } \\
\text { and rotational entropy, along with an intercept term. }\end{array}$} \\
\hline
\end{tabular}

- Table 4 The HOMO-LUMO gap and Chemical hardness values corresponds to the optimized structures of Uramustine and Synthesized drug compound at B3LYP/6-311++ ${ }^{* *}$ level of theory (in eV).

\begin{tabular}{|l|c|c|}
\hline Compound & HOMO-LUMO gap & Chemical hardness \\
\hline Uramustine & 4.29 & 2.15 \\
\hline Synthesized drug & 4.73 & 2.37 \\
\hline
\end{tabular}

OH-GLU71, 2.03 $\AA$ ). As depicted in figure the synthesized compound makes seven hydrogen bonding interactions at active site of the enzyme (PDB ID 2FST). Among them two interactions are came from the amino group, i. e., hydrogen atom interacts with oxygen of GLU71 and ASP168 (N-----H- GLU71 and H-ASP168, 2.73 Å and 1.80 $\AA$ ), the $\mathrm{CONH}_{2}$ makes three hydrogen bonding interactions with carbonyl group of LEU104, and ALA51 (H-----O = C-LEU104, O-LEU104 and O-ALA51, $2.25 \AA$, $2.38 \AA$ and $1.88 \AA$ ). The hydroxyl group present on the phenyl ring makes two interactions with HIS107 and MET109 (O-H-----O = C-HIS107, 1.96 A; H-O------H-MET109, 2.07 $\AA)$. MAP kinase is one of the major protein kinases, catalyzing phosphorylation of a number of substrates and thereby transuding signals from the cell membrane to the interior of the cell.

\section{DFT}

The HOMO-LUMO gap values of Uramustine showed 4.29 eV and interestingly synthesized compound was showed $4.73 \mathrm{eV}$. The ob- served gap values were indicates that the synthesized compound was more stable than the Uramustine. The bond length values and chemical hardness are listed in $>$ Table 4 . In addition the calculated chemical hardness value of synthesized compound was $2.37 \mathrm{eV}$ and it was higher than the Uramustine chemical hardness value $2.15 \mathrm{eV}$. Based on the maximum hardness principle [30] the consequence of higher chemical hardness value is a clear indication of maximum stability of the structure.

\section{Optimization}

Experimental design, 46 sets of experiments has been conducted by using BBSD and the experiments were performed within the parameters and their range, predicted results experimental results were presented in $\mathbf{F i g . 5 - 7 . ~}$

\section{Chemistry}

IR: $3368(\mathrm{OH}), 3312(\mathrm{NH}), 3044(\mathrm{Ar}-\mathrm{CH}), 2922\left(\mathrm{CH}_{2}-\mathrm{CH}\right), 1728$ $(C=O), 1643(C=N), 1631(C=C) ;{ }^{1} H$ NMR $\left(300 \mathrm{MHz}, D_{M S O}-d_{6}, \delta\right.$ ppm): 9.52 (s, 1H, OH), 8.69 (s, 4H, NH $\mathrm{N}_{2}$ ) 6.72-7.23 (m, 4H, Ar-H), 3.60 (s, 2H, CH $)_{2}$; MS (EI) m/z 260 [M + ]; Elemental analysis: calculated for $\mathrm{C}_{12} \mathrm{H}_{12} \mathrm{~N}_{4} \mathrm{O}_{3}$ : C, 55.38; $\mathrm{H}, 4.65 ; \mathrm{N}, 21.53$ found: $\mathrm{C}, 55.36$; $\mathrm{H}, 4.66$; N, 21.54 . 

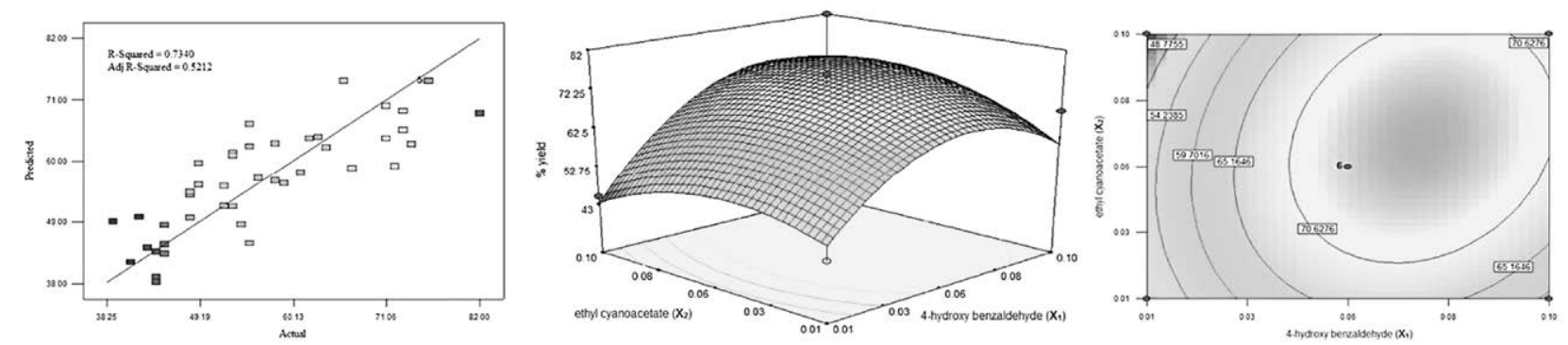

- Fig. 5 RSM's R2 value and significant effect of percentage yield
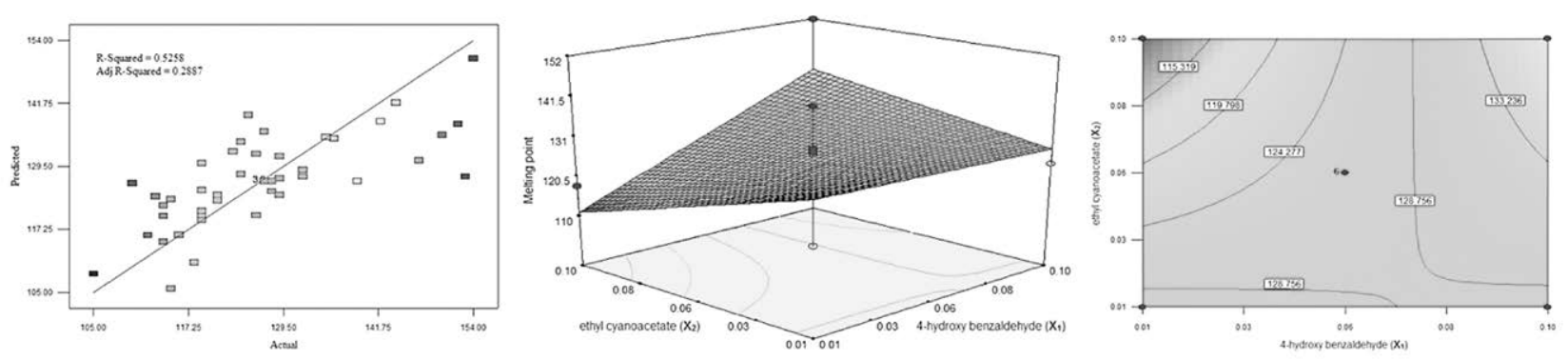

- Fig. 6 RSM's R2 value and significant effect of Melting point
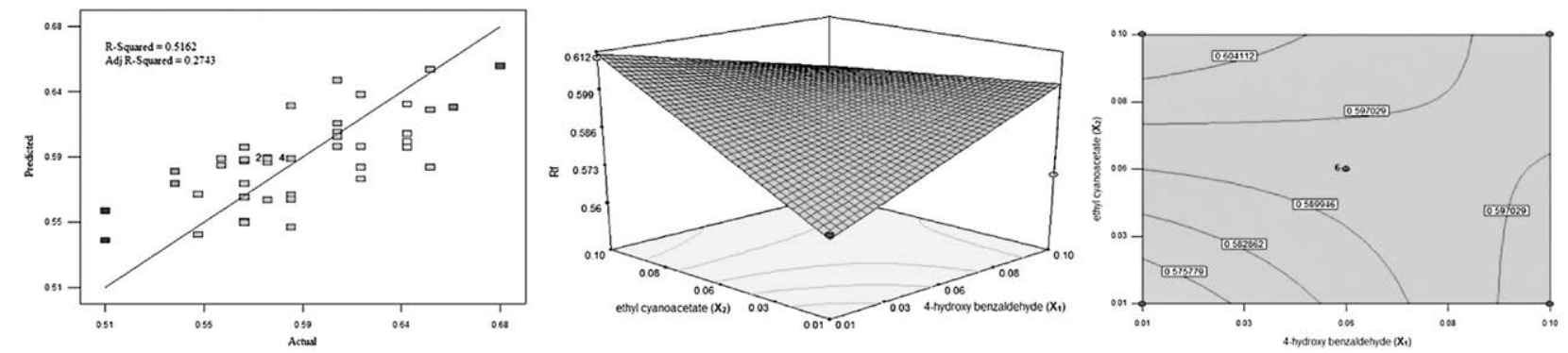

- Fig. 7 RSM's R2 value and significant effect of Rf value

\section{Discussion}

\section{Graph theoretical analysis}

The obtained outcome result from graph theoretical analysis was evidently highlights that the $\mathrm{p} 38 \alpha$ has crossed all parameters of threshold value. Therefore, $\mathrm{p} 38 \alpha$ is recognized as a significant protein on the whole network and it will be an ideal target to prevent the development of breast cancer cells.

\section{Insilico Modeling}

The observed in silico results were showing that the compound interacts with Glu 71 which is a conserved residue and this residue lies within the $\alpha C$ helix of ERK $1 / 2$ which is mainly it is required for saltbridging with $\beta 3$-lysin and the salt-bridging is essential for kinase to be active [31]. Since the designed compound interacts strongly with
Glu71 it would prevent salt-bridging and rendering the kinase inactive. Further, within the hydrophobic pocket III, Glu71 is capable of making a hydrogen bond with the donor residue.

The beginning activation segment of the DFG [expansion] motif spans is between 167 - 169 amino acids [31], within this region lies Asp 168 and it is interacts with the compound, therefore the compound is likely to affect activation of enzyme. In the enzyme hinge region ranges are from 106 - 109, interestingly the compound is capable of interacting with His 107 lying within the hinge region. This hinge region connects $\mathrm{N}$ - and $\mathrm{C}$ - lobes and interacts with ATP through hydrogen bond [31]. Therefore, the compound can able to effectively inhibit ERK2 since it can interact with 3 different amino acids positioned at 3 different crucial sites necessary for the activity of enzyme. In addition it has already been reported that small molecules inhibitors of protein kinases compete with hinge region to compete with ATP molecules [32]. 


\section{DFT}

The connection of DFT observed results were indicates that synthesized compound of 4-(4-hydroxybenzyl)-2-amino-6-hydroxypyrimidine-5-carboxamide is having more stable than the standard

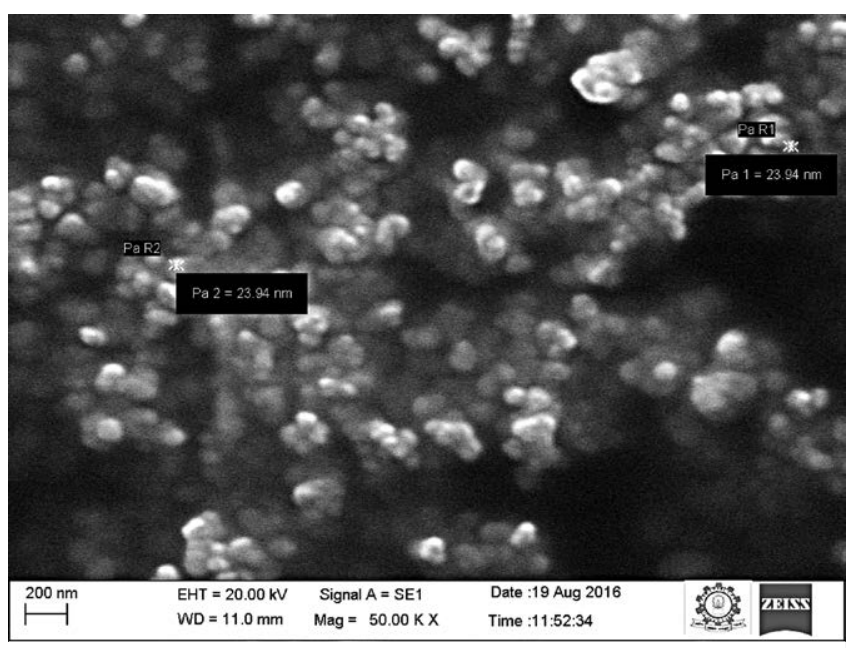

Fig. 8 The drug-copper nanocomposites configuration
Uramustine, hence the synthesized compound gained attraction for their further studies.

\section{Optimization}

The observed results were indicates that among the selected independent variables, 4-hydroxy benzaldehyde $\left(\mathbf{X}_{1}\right)$ and ethyl cyanoacetate $\left(\mathbf{X}_{\mathbf{2}}\right)$ has significant effects on maximum yield of 4-(4-hydroxybenzyl)-2-amino-6-hydroxypyrimidine-5-carboxamide (74.55-76\%), melting point $127^{\circ} \mathrm{C}$ and $R_{f}$ value of 0.59 .

- Table 5 The Percentage of viability of cell death.

\begin{tabular}{|l|c|c|}
\hline S. No & $\begin{array}{c}\text { Concentration of } \\
\text { Nanoparticles }(\boldsymbol{\mu g} / \mathbf{m L})\end{array}$ & \% of cell death \\
\hline 1 & 5 & 21.42 \\
\hline 2 & 10 & 29.36 \\
\hline 3 & 15 & 34.51 \\
\hline 4 & 20 & 46.43 \\
\hline 5 & 25 & 54.31 \\
\hline 6 & 30 & 61.5 \\
\hline 7 & 50 & 72.48 \\
\hline
\end{tabular}

- Table 6 Annotation of up-regulated proteins.

\begin{tabular}{|c|c|c|c|c|c|}
\hline Uniprot ID & $\begin{array}{l}\text { Protein Sequence } \\
\text { Coverage (\%) }\end{array}$ & Protein names & Gene names & $\begin{array}{l}\text { Number of Unique } \\
\text { Peptides }\end{array}$ & $\begin{array}{l}\text { Ratio/Fold } \\
\text { change } a^{*}\end{array}$ \\
\hline P06733 & 5.8 & Alpha-enolase & $\begin{array}{l}\text { ENO1 ENO1L1 MBPB1 } \\
\text { MPB1 }\end{array}$ & 12 & 1.5 \\
\hline P22314 & 12.9 & Ubiquitin-like modifier-activating enzyme 1 & UBA1 A1S9T UBE1 & 6 & 1.6 \\
\hline P11142 & 15.1 & Heat shock cognate $71 \mathrm{kDa}$ protein & $\begin{array}{l}\text { HSPA8 HSC70 HSP73 } \\
\text { HSPA10 }\end{array}$ & 11 & 1.7 \\
\hline V9HWG3 & 52.1 & Epididymis secretory protein Li 45 & HEL-S-45 & 9 & 1.7 \\
\hline P42338 & 13 & $\begin{array}{l}\text { Phosphatidylinositol 4,5-bisphosphate 3-kinase } \\
\text { catalytic subunit beta isoform }\end{array}$ & PIK3СB РIK3C1 & 5 & 1.8 \\
\hline P10809 & 23 & $60 \mathrm{kDa}$ heat shock protein, mitochondrial & HSPD1 HSP60 & 4 & 1.8 \\
\hline P07437 & 10.3 & Tubulin beta chain (Tubulin beta- 5 chain) & $\begin{array}{l}\text { TUBB TUBB5 OK/ } \\
\text { SW-cl.56 }\end{array}$ & 12 & 1.9 \\
\hline P08238 & 28.3 & Heat shock protein HSP 90-beta & $\begin{array}{l}\text { HSP90AB1 HSP90B } \\
\text { HSPC2 HSPCB }\end{array}$ & 12 & 1.9 \\
\hline P08670 & 14.7 & Vimentin & VIM & 7 & 1.9 \\
\hline P21333 & 23.7 & Filamin-A (FLN-A) & FLNA FLN FLN1 & 16 & 2.1 \\
\hline P35579 & 13.1 & Myosin-9 & MYH9 & 8 & 2.1 \\
\hline P08727 & 7.6 & Keratin, type I cytoskeletal 19 & KRT19 & 5 & 2.3 \\
\hline P04406 & 7 & Glyceraldehyde-3-phosphate dehydrogenase & $\begin{array}{l}\text { GAPDH GAPD } \\
\text { CDABP0047 OK/ } \\
\text { SW-cl.12 }\end{array}$ & 8 & 2.3 \\
\hline P68363 & 17.4 & Tubulin alpha-1B chain & TUBA1B & 6 & 2.7 \\
\hline P60709 & 16.1 & Actin, cytoplasmic 1 (Beta-actin) & АСТВ & 4 & 2.7 \\
\hline Q8IWP6 & 31.9 & Tubulin beta chain & & 7 & 3.1 \\
\hline O43707 & 23 & Alpha-actinin-4 & ACTN4 & 6 & 3.1 \\
\hline P07355 & 13.7 & Annexin A2 & $\begin{array}{l}\text { ANXA2 ANX2 ANX2L4 } \\
\text { CAL1H LPC2D }\end{array}$ & 6 & 3.1 \\
\hline P62736 & 9.8 & Actin, aortic smooth muscle (Alpha-actin-2) & $\begin{array}{l}\text { ACTA2 ACTSA ACTVS } \\
\text { GIG46 }\end{array}$ & 6 & 3.1 \\
\hline P13647 & 37.6 & Keratin, type II cytoskeletal 5 & KRT5 & 6 & 4.2 \\
\hline P05787 & 16.1 & Keratin, type II cytoskeletal 8 & KRT8 CYK8 & 5 & 5.6 \\
\hline
\end{tabular}


- Table 7 Annotation of down-regulated proteins.

\begin{tabular}{|l|c|l|l|c|c|}
\hline Uniprot ID & $\begin{array}{c}\text { Protein Sequence } \\
\text { Coverage (\%) }\end{array}$ & Protein names & Gene names & $\begin{array}{c}\text { Number of } \\
\text { Unique Peptides }\end{array}$ & $\begin{array}{c}\text { Ratio/Fold } \\
\text { change a }\end{array}$ \\
\hline P13639 & 15.9 & Elongation factor 2 & EEF2 EF2 & 4 \\
\hline P12814 & 24.3 & Alpha-actinin-1 & ACTN1 & 5 \\
\hline P14618 & 18.7 & Pyruvate kinase PKM & PKM OIP3 PK2 PK3 PKM2 & 21 & 0.1 \\
\hline P05783 & 12.9 & Keratin, type I cytoskeletal 18 & KRT18 CYK18 PIG46 & 5 & 0.3 \\
\hline P07900 & 36.1 & Heat shock protein HSP 90-alpha & HSP90AA1 HSP90A HSPC1 HSPCA & 4 & 0.3 \\
\hline P02545 & 8.1 & Prelamin-A/C & LMNA LMN1 & 4 & 0.4 \\
\hline P60174 & 45.2 & Triosephosphate isomerase (TIM) & TPI1 TPI & 12 & 0.4 \\
\hline P11021 & 22.7 & 78kDa glucose-regulated protein & HSPA5 GRP78 & 4 & 0.4 \\
\hline P35222 & 18.3 & Catenin beta-1 & CTNNB1 CTNNB OK/SW-cl.35 PRO2286 & 4 & 4 \\
\hline Q16665 & 9.6 & Hypoxia-inducible factor 1-alpha & HIF1A BHLHE78 MOP1 PASD8 & 0.5 \\
\hline P42224 & 33.1 & $\begin{array}{l}\text { Signal transducer and activator of } \\
\text { transcription 1-alpha/beta }\end{array}$ & STAT1 & 4 & 0.5 \\
\hline F5H5D3 & 14.9 & Tubulin alpha chain & TUBA1C & 0.5 \\
\hline A0A024R321 & 26.8 & Filamin B, beta & FLNB hCG_27732 & 6 \\
\hline
\end{tabular}

- Table 8 KEGG Pathway enrichment analysis.

\begin{tabular}{|l|l|c|c|l|}
\hline $\begin{array}{l}\text { Pathway } \\
\text { ID }\end{array}$ & Pathway description & $\begin{array}{c}\text { Observed } \\
\text { gene count }\end{array}$ & $\begin{array}{c}\text { False } \\
\text { discovery rate }\end{array}$ & Matching proteins in your network (labels) \\
\hline 4510 & Focal adhesion & 6 & $3.76 \mathrm{E}-05$ & ACTB,ACTN1,ACTN4,CTNNB1,FLNA,PIK3CB \\
\hline 4670 & $\begin{array}{l}\text { Leukocyte transendothelial } \\
\text { migration }\end{array}$ & 5 & $3.76 \mathrm{E}-05$ & ACTB,ACTN1,ACTN4,CTNNB1,PIK3CB \\
\hline 4530 & Tight junction & 5 & $5.13 \mathrm{E}-05$ & ACTB,ACTN1,ACTN4,CTNNB1,MYH9 \\
\hline 4520 & Adherens junction & 4 & 0.000116 & ACTB,ACTN1,ACTN4,CTNNB1 \\
\hline 5200 & Pathways in cancer & 6 & 0.000193 & CTNNB1,HIF1A,HSP90AA1,HSP90AB1,PIK3CB,STAT1 \\
\hline 5215 & Prostate cancer & 4 & 0.000201 & CTNNB1,HSP90AA1,HSP90AB1,PIK3CB \\
\hline 4915 & Estrogen signaling pathway & 4 & 0.000261 & HSP90AA1,HSP90AB1,HSPA8,PIK3CB \\
\hline 4810 & $\begin{array}{l}\text { Regulation of actin } \\
\text { cytoskeleton }\end{array}$ & 5 & 0.000287 & ACTB,ACTN1,ACTN4,MYH9,PIK3CB \\
\hline 5205 & Proteoglycans in cancer & 5 & 0.000332 & ACTB,CTNNB1,FLNA,HIF1A,PIK3CB \\
\hline
\end{tabular}

\section{Chemistry}

The IR, ${ }^{1} \mathrm{H}-\mathrm{NMR}$, mass spectroscopy and elemental analyses for the new compound are in accordance with the assigned structures. The IR spectrum of compound showed bands of hydroxy group at $3368 \mathrm{~cm}^{-1}$ and amine group stretching bands appears at $3312 \mathrm{~cm}^{-1}$. The appearance of a strong intensity band in the IR spectra of compound in the range of $1728 \mathrm{~cm}^{-1}$ attributable to $\mathrm{C}=\mathrm{O}$ and it provides a strong evidence for the condensation and also confirms the formation of the title compound. The proton magnetic resonance spectra of pyrimidine derivative have been recorded in $\mathrm{CDCl}_{3}$. In this signals appear at $9.52(\mathrm{~s}, 1 \mathrm{H}, \mathrm{OH}), 8.69(\mathrm{~s}$, $4 \mathrm{H}, \mathrm{NH}_{2}$ ), 6.72-7.23 (m, $\left.4 \mathrm{H}, \mathrm{Ar}-\mathrm{H}\right), 3.60$ (s, $2 \mathrm{H}, \mathrm{CH}_{2}$ ) ppm respectively. The position and presence of proton signals in the ${ }^{1} \mathrm{H}$-NMR spectra of final compounds and mass spectra were confirms further the title moiety. All these observed facts clearly envisages that the 4-(4-hydroxy benzyl)-2-amino-6-hydroxypyrimidine-5-carboxamide formation as indicated in > Fig. 3 and it confirms the proposed structure. The characterization of formulated nanoparticles by SEM analysis and X-ray diffraction reports were confirm the formation of copper-drug nanoparticles that of less than $30 \mathrm{~nm}$ diameter in size $\mathbf{r}$ Fig. $\mathbf{8}$.

\section{Anticancer activity}

The in silico modeling report was encouraging us to perform in vitro anticancer activity and it was screened against MCF7 cancer cell lines by using MTT assay. In a dose-dependent manner the 4-(4-hydroxybenzyl)-2-amino-6-hydroxypyrimidine-5-carboxamide nanoparticles was having capability to decrease viability of cells. The observed results with $5 \mu \mathrm{g} / \mathrm{mL}$ concentration was decreases $21 \%$ viability of cell death as shown in, $25 \mu \mathrm{g} / \mathrm{mL}$ concentration was decreases $54 \%$ viability of cell death and $72 \%$ cell death was observed with $50 \mu \mathrm{g} / \mathrm{mL}$ concentration of nanoparticles. The findings of above results were directly indicating that the increasing concentration of nanoparticles was directly decreases viability of cell death $>$ Table 5 .

\section{Quantitative proteomics studies}

Quantitative proteomics was performed for our drug to understand the molecular mechanism at its functional level. After applying the filtering criteria of greater than 2 unique peptides with $5 \%$ FDR and a Q-value of zero 34 proteins were differentially expressed in treatment groups. Among them, 21 proteins were up regulated with intensity ratio $>1.5 \triangleright$ Table 6 and 13 proteins were down regulated 
proteins with intensity ratio $<0.05>$ Table 7 . Gene ontology and interactive pathway maps were represented in the Further, KEGG pathway enrichment analysis was performed and key pathways and its regulatory proteins were represented in the $\mathbf{T a b l e ~} \mathbf{8}$. Over all, the identified regulatory pathways and differentially expressed proteins on drug treatment were well established and linked with the major regulatory networks in carcinogenesis, tumor progression and metastasis in multiple cancer types.

\section{Conclusion}

A general method has been developed for the synthesis of 4-(4-hydroxybenzyl)-2-amino-6-hydroxypyrimidine-5-carboxamide. This process involved in the addition of ethyl cyanoacetate, 4-hydroxy benzaldehyde and guanidine hydrochloride with various temperatures and rotation per minute (rpm). On the basis of optimization measurement, the synthesis of 4-(4-hydroxybenzyl)2-amino-6-hydroxypyrimidine-5-carboxamide has been proposed for achieve high yield with accuracy of physiochemical parameters like melting point and $R_{f}$ value. The optimization behavior of title compound was studied which showed that more positive potential value of the yield $82 \%$ as compared to those for corresponding synthesis. The in vitro biocompatibility study was highlighting that 4-(4-hydroxybenzyl)-2-amino-6-hydroxypyrimidine-5-carboxamide nanoparticles was having significant cell viability and proliferation and $92 \%$ MCF7 cellular death was confirming that it was aligned with in silico modeling study report. Therefore the formulated nanoparticles might be an exclusive carrier in the connection of drug delivery against cancer activity and we introduced graph theoretical analysis, density functionality theory and proteomics reports are having a great impact and it will open a new resource in the identification of alternative treatment of various cancers.

\section{Acknowledgments}

The authors gratefully acknowledge the SAIF/CIL, Punjab University, Chandigrah, India for the spectral analysis of the title compounds used in this study. The authors also thank Karavali College of Phamcacy, Managalore, Karnataka and M S Ramaiah University of Applied Sciences, Bangalore, Karnataka for providing infrastructure as well as software facilities to carry out this research work.

\section{Conflict of Interest}

Authors declare there is no conflict of interest.

\section{References}

[1] Amr A.E.-G.E., Maigali SS, Abdulla MM. Synthesis, and analgesic and antiparkinsonian activities of thiopyrimidine, pyrane, pyrazoline, and thiazolopyrimidine derivatives from 2-chloro-6-ethoxy-4-acetylpyridine. Monatshefte für Chemie-Chemical Monthly 2008; 139: 1409-1415

[2] Said SA, Amr A.E.-G.E., Sabry NM et al. Analgesic, anticonvulsant and anti-inflammatory activities of some synthesized benzodiazipine, triazolopyrimidine and bis-imide derivatives. European Journal of Medicinal Chemistry 2009; 44: 4787-4792
[3] Xie F, Zhao H, Zhao L et al. Synthesis and biological evaluation of novel 2, 4, 5-substituted pyrimidine derivatives for anticancer activity. Bioorganic \& Medicinal Chemistry Letters 2009; 19: 275-278

[4] Amr A-GE, Mohamed AM, Mohamed SF et al. Anticancer activities of some newly synthesized pyridine, pyrane, and pyrimidine derivatives. Bioorganic \& Medicinal Chemistry 2006; 14: 5481-5488

[5] Li ], Zhao YF, Zhao XL et al. Synthesis and Anti-tumor Activities of Novel Pyrazolo [1, 5-a] pyrimidines. Archiv der Pharmazie 2006; 339: 593-597

[6] Lombardo LJ, Lee FY, Chen P et al. Discovery of N-(2-chloro-6-methylphenyl)-2-(6-(4-(2-hydroxyethyl)-piperazin-1-yl)-2-methylpyrimidin4-ylamino) thiazole-5-carboxamide (BMS-354825), a dual Src/Abl kinase inhibitor with potent antitumor activity in preclinical assays. Journal of Medicinal Chemistry 2004; 47: 6658-6661

[7] DeGraw JI, Christie PH, Colwell WT et al. Synthesis and antifolate properties of 5, 10-ethano-5, 10-dideazaaminopterin. Journal of Medicinal Chemistry 1992; 35: 320-324

[8] Quintela J, Peinador C, Botana L et al. Synthesis and antihistaminic activity of 2-guanadino-3-cyanopyridines and pyrido [2, 3-d]pyrimidines. Bioorganic \& Medicinal Chemistry 1997; 5 : 1543-1553

[9] Zakharov A, Gavrilov MY, Novoselova G et al. Synthesis and antimicrobial activity of 1-aryl-2-vinyl-7-methyl-1, 4-dihydropyrido [2, 3-d] pyrimidin-4-ones. Pharmaceutical Chemistry Journal 1996; 30: 703-704

[10] Saladino R, Ciambecchini U, Maga G et al. A new and efficient synthesis of substituted 6-[(2'-Dialkylamino) ethyl] pyrimidine and 4-N, $\mathrm{N}$-Dialkyl-6-vinyl-cytosine derivatives and evaluation of their anti-Rubella activity. Bioorganic \& Medicinal Chemistry 2002; 10: 2143-2153

[11] Madhavan GR, Chakrabarti R, Vikramadithyan RK et al. Synthesis and biological activity of novel pyrimidinone containing thiazolidinedione derivatives. Bioorganic \& Medicinal Chemistry 2002; 10: 2671-2680

[12] White DC, Greenwood TD, Downey AL et al. Synthesis and anticonvulsant evaluation of some new 2-substituted-3-arylpyrido [2, 3-d] pyrimidinones. Bioorganic \& Medicinal Chemistry 2004; 12: 57115717

[13] Nam G, Yoon CM, Kim E et al. Syntheses and evaluation of pyrido [2, 3-d] pyrimidine-2, 4-diones as PDE 4 inhibitors. Bioorganic \& Medicinal Chemistry Letters 2001; 11: 611-614

[14] Shaabani A, Rahmati A, Farhangi E. Water promoted one-pot synthesis of $2^{\prime}$-aminobenzothiazolomethyl naphthols and 5-(2'-aminobenzothiazolomethyl)-6-hydroxyquinolines. Tetrahedron Letters 2007; 48: 7291-7294

[15] Vugts D], Koningstein MM, Schmitz RF et al Multicomponent synthesis of dihydropyrimidines and thiazines. Chemistry-A European Journal 2006; 12: 7178-7189

[16] Kim YB, Choi EH, Keum G et al. An efficient synthesis of morpholin2-one derivatives using glycolaldehyde dimer by the Ugi multicomponent reaction. Organic Letters 2001; 3: 4149-4152

[17] Lee D, Sello JK, Schreiber SL. Pairwise use of complexity-generating reactions in diversity-oriented organic synthesis. Organic Letters 2000; 2: 709-712

[18] Wijngaard HH, Brunton N. The optimisation of solid-liquid extraction of antioxidants from apple pomace by response surface methodology. Journal of Food Engineering 2010; 96: 134-140

[19] Bezerra MA, Santelli RE, Oliveira EP et al. Response surface methodology (RSM) as a tool for optimization in analytical chemistry. Talanta 2008; 76: 965-977

[20] Gan C-Y, Latiff AA. Optimisation of the solvent extraction of bioactive compounds from Parkia speciosa pod using response surface methodology. Food Chemistry 2011; 124: $1277-1283$ 
[21] Guille A, Chaffanet M, Birnbaum D. Signaling pathway switch in breast cancer. Cancer Cell International 2013; 13: 1

[22] Pearson G, Robinson F, Beers Gibson T et al. Mitogen-activated protein (MAP) kinase pathways: Regulation and physiological functions 1. Endocrine Reviews 2001; 22: 153-183

[23] Guille A, Chaffanet M, Birnbaum D. Signaling pathway switch in breast cancer. Cancer Cell International 2013; 13: 66

[24] Scardoni G, Petterlini M, Laudanna C. Analyzing biological network parameters with CentiScaPe. Bioinformatics 2009; 25: 2857-2859

[25] Senthilvel P, Lavanya P, Kumar KM et al. Flavonoid from Carica papaya inhibits NS2B-NS3 protease and prevents Dengue 2 viral assembly. Bioinformation 2013; 9: 889-895

[26] Devlin F, Finley J, Stephens P et al. Ab-Initio Calculation of Vibrational Absorption and Circular-Dichroism Spectra Using Density-Functional Force-Fields-a Comparison of Local, Nonlocal, and Hybrid Density Functionals. Journal of Physical Chemistry 1995; 99: 16883-16902
[27] Fletcher R, Powell M]. A rapidly convergent descent method for minimization. The Computer Journal 1963; 6: 163-168

[28] Valiev M, Bylaska EJ, Govind N et al. NWChem: A comprehensive and scalable open-source solution for large scale molecular simulations. Computer Physics Communications 2010; 181: 1477-1489

[29] Panneerselvam T, Sivakumar V, Arumugam S et al. Design, Network Analysis and In Silico Modeling of Biologically Significant 4-(substituted benzyl)-2-Amino-6-HydroxyPyrimidine-5-Carboxamide Nanoparticles. Drug Research 2017; 67: 289-301

[30] Scheiner S, Gu Y, Kar T. Evaluation of the H-bonding properties of $\mathrm{CH} \cdots \mathrm{O}$ interactions based upon NMR spectra. Journal of Molecular Structure: THEOCHEM 2000; 500: 441-452

[31] Roskoski R. ERK1/2 MAP kinases: Structure, function, and regulation. Pharmacological research 66: 2012; 105-143

[32] Zhang J, Yang PL, Gray NS. Targeting cancer with small molecule kinase inhibitors. Nature Reviews Cancer 2009; 9: 28-39 